Covered in: Web of Sciences (WOS); EBSCO; ERIH+; Google Scholar; Index Copernicus; Ideas RePeC; Econpapers; Socionet; CEEOL; Ulrich ProQuest; Cabell, Journalseek; Scipio; Philpapers; SHERPA/ROMEO repositories; KVK; WorldCat; CrossRef; CrossCheck

2018, Volume 9, Issue 1, pages: 7-21 | doi: https://doi.org/10.18662/po/02

\section{Does Charlie Gard Deserve to be Taken Off Life Support?}

\section{Abiola BAMIJOKO- OKUNGBAYE ${ }^{1}$}

${ }^{1} \mathrm{PhD}$ researcher, University of Sofia, Bulgaria, bamijoko@yahoo.com

\begin{abstract}
Charlie's death was a case that took the public aback by the decision taken at the Great Ormond Street Hospital (GOSH) in London. Charlie Gard suffers from a rare disease called mitochondrial DNA disease, a malady that engenders the doctors at Great Ormond Street hospital in London to reach a unanimous decision to turn off his life support as there is no treatment available to treat him. According to the doctors involved, they have weighed his chances of recovery apparently his chances of survival are bleak. Because of this, his parents were denied the application of an alternative therapy which is possible in the United States. This paper thematizes bioethics principles to judge the decisions taken by the doctors in London. I intend to argue that their decision is incompatible with our conceptual idea of a free society. This paper will conclude that one significant principle of bioethics/liberal democracy was ditched, ergo making their decision questionable.
\end{abstract}

Keywords: ethics, medical ethics, bioethics, postmodern society, medicine.

How to cite: Bamijoko-Okungbaye, A. (2018). Does Charlie Gard Deserve to be Taken off Life Support?. Postmodern Openings, 9(1), 7-21. https://doi.org/10.18662/po/02 


\section{Introduction}

Charlie's case entails 11 months old boy born with MDDS, mitochondrial DNA depletion syndrome, a genetic disorder that prompts progressive brain damage and muscle failure. For the sake of clarity, this paper is divided into six parts. The first part is to address the issues at hand, introducing the case, the second part is looking at the national and international status of Charlie's autonomy, the third part will review the courts' decisions and their impact on the case, the fourth part will attempt to clarify whether the arguments supported by the medical team are the best option, the fifth part will look at the politics of bioethics regarding Charlie's case and in the final part, insights won will be used to draw conclusion. Lucidly, the bone of contention is between the parents and the medical team involved pertaining experimental treatment offered by a New York Doctor, Michio Hirano. Hirano is a neurologist researching on an experimental treatment employing nucleoside supplementation.

He was consulted to visit Charlie in London to help with his treatment, prior to his visit Charlie suffered seizures that affected his brain, resulting in brain damage. The medical team in London concluded that the treatment would be fruitless, given the fact that Charlie's brain damage is irreversible. The dispute is whether the experimental treatment offers an antidote to Charlie's suffering. This case occurred in 2017, galvanizing various academics, ethicists, politicians, and pontiff. They step in to give their take on the issue. The malady affecting Charlie engenders the doctors to give a prognostication at Great Ormond Street Hospital (GOSH) in London. The medical team reach a unanimous decision to turn off his life support as there is no treatment presently to treat him. According to the medical team involved, no pharmacology arrangement will reverse the severe damage in his brain.

Conclusively, the medical team determined his chances of recovery to be very slim.As a consequence, his parents were denied the application of an alternative therapy which is possible in the United States ostensibly their right to autonomy was withheld based on the contingent that this may aggravate his suffering. A closer look at the timeline of events is as follows, in October 2016, Charlie arrived at the Great Ormond Street Hospital and was immediately put on a ventilator because self-ventilation has become impossible. His diagnosis was confirmed in November 2017. At the same period, the ethics team at Great Ormond hospital advised the medical team to refrain from administering Charlie tracheostomy (Yates \& Anor, 2017) 
The public grapples with the decisions taken by the doctors which result in Pope Francis and President Trump intervening and spelling out their intention to render help. The public cannot comprehend why Charlie was not given a chance to try the available alternative therapy. The public was taken by surprise with the doctors' decision, resulting in a GOFUNDME page set up online to raise funds for his treatment. The nucleoside alternative therapy was applied to Art Jr. when he was just 18 months. Now Art Jr. is 6 years old and getting stronger every day as his parents, put it. Charlie's case delineated above is the best case to address the principles of biomedical ethics applied, namely autonomy (respecting patient's wishes), beneficence(doing good), non-maleficence, (avoiding harm) and justice (fairness in the provision of care). As this case illustrates, there is a clear tension among all these tenets of medical ethics. In regarding justice, European Union court sides with the doctors' decision to take Charlie off life support. Is their decision justified? It is my intention to argue that the doctors' decision and the European court of justice decision are incompatible with the values of a liberal democracy. Their decision is paternalistic and not compatible with our idea of a free society. In Charlie's Gard case, it is essential before we go in-depth in this paper to outline the opinion of the doctors and ethicists involved.

According to their findings, their decision is based on protecting Charlie and saving him from unnecessary pain. As any parent would act, a glimmer of hope of a potential treatment in New York leads Charlie's parents to insist on an alternative treatment. In January 2017, Hirano was invited to examine Charlie in London but could not make the trip. Charlie's parents were ready to move Charlie to the US for treatment since the MRI performed by Hirano in December 2016 showed no severe damage, this is according to the public record of April 2017("Great Ormond Street Hospital v Yates \& Ors [2017] EWHC 972 (Fam) (11 April, 2017).A request was made by the medical team in February 2017 at the court in London to suspend Charlie parents' autonomy. The request was granted based on the assumption that the alternative therapy provides no evidence that Charlie would respond to treatment. The medical team argued that they have the latitude to know this due to the fact that they possess Charlie's medical records and are very confident in their findings. For them, allowing him to travel equates exacerbating his pain. In line with the doctors involved, the seizures that happened in January 2017 have resulted in irreversible encephalopathy, rendering any treatment ineffectual. Consequently, the medical team recommend palliative care for Charlie. The doctors intend to continue the pharmacology arrangement. 
Subsequently, as reported by the Sun (Adu, 2017), in January 2017, Charlie's parents begin seeking funds which by the end of April 2017, donations have risen above 1.3 Million pounds. In June 2017, the high court supported the views presented by the medical team in London for Charlie to be taken off life support, roughly the same time in June, Congressmen from the United States offered their support to speed up the process of transferring Charlie to the US for treatment. In July 2017 (Rabin, 2017), doctors in New York were apt to send treatment to London but ethicists at Great Ormond Street Hospital had refused consent. Is the decision taken by the Court in London internationally applicable and solidifies the United Nations treaty which the United Kingdom is part of? I shall now look at national and international framework in relation to Charlie's case.

\section{The National and International status of Charlie's Autonomy}

I am inclined to define children in alignment with the United Nations proclamation that states individuals below the age of 18 years should be described as children. Globally, most countries definition of children falls below the range of 18-21 years old. Evidently, we agree that children rights are internationally binding agreements under the aegis of United Nations standards. All countries have ratified this right except Somalia and the United States of America. A child is described according to this treaty as a person under the age of 18 years. This treaty unequivocally accepts the family as an inherent part of the society and this core understanding was underscored in the treaty with the presentation of the parent's role as the primary caregivers with full responsibility for the upbringing of their children. The agreement proposes that the government supports the parents in fulfilling this role. Certainly, the children UK act 1989 espouses the United Nations framework when it emphasises the notion that children are best supported by their own families. The 1989 act even instructs local authorities, courts and other governmental entities within the state to protect this fundamental right. At the same time, the law reserves the right for intervention when parents are not playing the role designated to them within the act. I will shortly look at the courts' decisions to see whether they aligned with the statute set forth by the United Nations and United Kingdom children act 1989. 


\section{The Courts' decisions}

In Charlie's Gard case, his parents and the medical team could not reach a mutual agreement on how to proceed further prompting the courts to chime in on the request of GOSH. Four requests were put in motion:

- Charlie lacks the autonomous power to make a decision for himself.

- Life support should be stopped.

- The medical team are right to offer palliative care only.

- It is within the law and in Charlie's best interest not to try an alternative therapy.

Hirano's evidence was produced in the court and he underlines the theoretical chance of improving Charlie's current situation. But, he does concede that the treatment would not restore the brain structure back to its initial functionality. Conversely, he would be interested in treating Charlie if his parents are in the position to fund the treatment and he would listen to the recommendation of his intensive care unit before proceeding with the treatment.

The judge presiding over the case considers Hirano's evidence during the final decision-making process. As the Judge puts it, reiterating Hirano's testimony. Hirano claims that it is difficult for him to make a complete diagnosis given the fact that he has not seen Charlie. He opines that the electroencephalogram at its current state is bad. At this current stage, Charlie is in the terminal stage of his illness. He does accept the position of the court and does concede that his treatment might not help but the alternative is death. Concurrently, ready to do what he can to assist Charlie. The judge iterates, saying based on the evidence submitted by Hirano, there is no scientific evidence of any future improvement. The therapy might sound promising but the irreversible brain damage remains.

Testimony was also put forward by Charlie's parents, they opine that the nucleoside therapy would improve the condition of their son. The court called a guardian who testified the risk of pain, confirming the minimal chance of recovery. According to public records, reported, on $11^{\text {th }}$ April 2017, the judge endorses the requests put in motion by the medical team of Great Ormond Street Hospital in London (Fouzder, 2017). The case was appealed with a new evidence dated and signed in May 2017 by Hirano. The court dismissed this case citing that the new evidence is likely not to change Charlie's condition. On June $19^{\text {th, }} 2017$ Charlie's parents requested an intervention of the European court of human rights. Charlie's parents 
believe that under the articles 2,5 and 8 of the European convention on human rights, the court's decision in London was based on conjecture because Charlie's and parents' rights were disregarded when the court made their pronouncement. The European court heard the case under the title Gard and Others versus the United Kingdom. Unsuccessfully for Charlie's parents, the case was deemed inadmissible. As the court puts it in their announcement:

"Therefore, examining the decisions taken by the domestic courts in light of those considerations, the Court recalls that they were meticulous and thorough; ensured that all those concerned were represented throughout; heard extensive and high-quality expert evidence; accorded weight to all the arguments raised; and were reviewed at three levels of jurisdiction with clear and extensive reasoning giving relevant and sufficient support for their conclusions at all three levels. Accordingly, the Court does not see any element suggesting that those decisions could amount to an arbitrary or disproportionate interference. Therefore, this part of the complaint is manifestly ill-founded ("HUDOC - European Court of Human Rights," 2017). In view of the above, it is appropriate to discontinue the application of Rule 39 of the Rules of Court.

Suppose this ruling could yield a conclusion that is satisfactory to the case. Nevertheless, I am inclined to believe that Charlie's parents would deem the ruling unacceptable. Is this decision Charlie's best interest?

\section{Is beneficence the best approach, in this case, negating Charlie's autonomy?}

Charlie 's autonomy as eleven months old baby according to free society standard belongs to his parent until he reaches adulthood, this may vary from country to country, usually from 18 years of age. This observation is also anchored within the international legal framework stipulated by the United Nations. From this age upward, one is deemed capable of making her own decisions. In this case, emerges a conflict in which Charlie's doctors will eventually have to deal with. This conflict of autonomy and informed consent versus paternalism and the doctors' intervention (beneficence) are at friction in this particular case. On one hand, autonomy is the principle of non-interference and the right to self-determination, informed consent is the concept that every human being of adult age and of sound mind have a right to determine what shall be done with her own body. It is the exercise of a choice after being informed of the process and risks of a medical treatment whereas on the other hand lies paternalism, the interference with the 
limitation of, or suspending of individual autonomy justified by reasons referring exclusively to the welfare or needs of the person being overridden.

Juxtaposing autonomy and other principles, we recognize patient's freedom of choice. In this case, Charlie's parents request to apply alternative therapy was denied by the doctors and the court. Doctors' denial of alternative treatment in Charlie's case was based on doing good to Charlie's overall health(beneficence), avoiding further pain to his life(nonmaleficence), and court denial (Justice), suggesting fairness in the provision of care. This provokes the question, is Charlie's autonomy respected? (Ackerman, 1982) in his report called "Why Doctors should intervene" sheds light on various kinds of constraints that would initiate paternalistic intervention. These include:

- Physical constraints such as prison or bodily prevention.

- Cognitive constraints, an example is someone with the inability to understand the information given to them and psychological objectively this would involve someone who is depressed or suffers from something like Alzheimer's disease.

- Social constraints are when a peer pressure or the cultural background of a patient playing a role in autonomous decisions.

As we shall see in this piece that Charlie's parents are cognitively capable of making this decision which they did but was rejected.

The doctors at the Great Ormond Street hospital in London argue that they support beneficence and non-maleficence. It should be impossible to enforce these values on others when there is a therapy that could help Charlie from his predicament. As stated by the doctors involved, the therapy is experimental and cure is not guaranteed. Can this statement be said with certitude? Charlie is underage and cannot make life decision about his wellbeing. Nonetheless, the next person in line is his parents according to free society liberties. We are responsible for our underage children. This autonomy is inscribed in our free societal values. In a free society where selfownership is recognized, which I consider to be one of the greatest human rights, rejecting his parents' wishes and their autonomy is not justifiable. The request made by Charlie's parent to try another therapy approach is neither immoral nor inimical. His parents are of sound mind, proving their cognitive capability to make such decisions. The doctors willing to try the nucleoside approach took the Hippocratic oath as well and are under the jurisdiction of the United States healthcare guidelines.

The decisions made by the doctors are based solely on the reason that no therapy would save Charlie's life. I do understand the role which cross-cultural ethics play in granting the patient full autonomy. But, I also 
understand that doctors must have to draw the line in which they respect patient's autonomy. Can we justify the rejection of his parents' autonomy? Who are we to undermine a person of sound mind, in this case, Charlie's parent their freedom of choice? In this particular case, Charlie's parents did not cross the line of rejection of their autonomy. This right to autonomy basically gives them the right of self-ownership as a deeper moral relationship. The only case in this situation where their autonomy can be rejected is if they lack decision-making capacity. Incapability to make decisions could result in making decisions that are contrary to their best interest, hence rejecting their autonomy.

In this case, we have parents requesting for an alternative treatment for their kid who they have jurisdiction over. If decision-making capacity is intact, the physicians should generally respect the parents' choices. If their decision making capability is impaired, other arrangements could be made for making health decisions on behalf of Charlie. The liberty we enjoy in a free society entails our right to be imperfect so therefore, it is unjustified to compel our way of thought on others. The doctors' decision to take Charlie off life support is in my opinion, a medical opinion which is open to ambiguity due to the fact of the success story of Art Jr. in the United States who is a survival of the same illness. The doctors can claim that they understand Charlie's and his parents' pain and agony, but in all seriousness and fairness, can they physically feel their pain?

\section{Charlie's Life and Politics}

His parents' effort to save Charlie was futile, their move to turn to the highest office in their country for assistance was denied, Theresa May, the British prime minister returned the case back to the doctors. Charlie's parents find themselves in a paternalistic situation, the doctor knows the best scenario, which suspends their fundamental human right. Here is the implication that may not be positive as a result of this decision, their chance for a potentially life-saving treatment for Charlie was rejected. The argument propagated by her office is that her hands were tied in letting Charlie travel abroad for treatment. She is sympathetic to the doctors' decision at London hospital to turn off the life-saving tubes for Charlie, adding that she cannot overrule the UK and Europe courts. She does concede the fact that, it is an imaginable situation to be in and she even shows understanding when she says: 
"I fully understand and appreciate that any parent in this circumstances would want to do everything possible and explore every option for their seriously ill child" (Walker, 2017).

This is plain in my claim that his parents' demand was within a moral line although the prime minister supported the doctors' decision. The rationality behind her decision is that the medical decisions should be led by expert medical opinion, aligned with the court and as her government puts it, with Charlie's best interest at heart. May does not put the theoretical chance of helping Charlie presented by Hirano when she made this abovequoted stance. Autonomy as this case shows is widely neglected as a value. I do not propose that autonomy topples any ethical tenets but rather be weigh in when making other ethical decisions. A balanced approach, I envisage will be the best ethical approach of the future. Alastair Campbell (Fulford, Gillett, \& Soskice, 1994) by contrast, criticises autonomy as he argues for dependency rather autonomy as the foundational tenet of medicine. He proposes an expansion of medical ethics to make space for other dimensions of ethics. It is discernible that Campbell does not call for autonomy to be ditched. He is more concerned with the domination of autonomy as a foundational value, according to him, the domination of autonomy in bioethics has caused autonomy to become unbalanced as a basis for medical care decision-making.

Campbell views dependency as part of our constitution, humans being dependent beings. As he puts it, it is during the health struggles that we recognize our vulnerability and dependency. In a nutshell, Campbell notes that dependency is the foundational value in medical ethics, making it a top value. If I were to accept his arguments as a prima facie fact, his espousal of making dependency the foundational value is unbalanced if his intention were to create a balanced approach. It can be clearly seen in Charlie's case that pushing any value as a top value could move decisions into an unbalanced spectrum. There is a familiar likeliness to make the following assertion that Campbell might welcome the decision made in London. Although, I have no criterion of verification still I understand he is a proponent of setting a top value in ethics. As I delineated above, Campbell could support courts and medical team treating Charlie. I am not considering this assumption to be factual but rather based on analysing his intention to make dependency a top value in medical ethics. The courts and Theresa May, the British prime minister definitely believe that the medical team in London got it right.

Roughly speaking, if Charlie's autonomy does not belong to his parents, who owns it? Neither doctors nor states can claim this ownership, 
this would blatantly contradict the United Nation's treaty adopted by the UK government and also the children act of 1989. Both spell out neatly, the pivotal role of the family. Could it be that the experts misunderstand the concept of autonomy and ownership? In my judgement, the society plays a role in making sure that our children become the best person that they can be. Society in this context includes the parents, doctors and the government. As the children act 1989 stipulated, the state can jump in if parents and doctors are not on the same page regarding the treatment of their child. In addition, the children act 1989 outlines the scope by which parents' and doctors' decision supersedes one another.

For this reason, I take the view that children belong to us all, particularly in the case when they are cognitively incapable of making decisions for themselves and during the time of disputes with the carer. During a dispute, the decision should be collectively made for the betterment of our children. The issue here is when we tend to make a collective decision, we make decisions based on rules. In so doing, we live parents in a legal limbo pushing them to cooperate willy-nilly. Let's take beneficence, for example, the act of doing good which one can also term as looking for the best interest of a child. This rule propagates that we must do what is best for a child without personal interests or personal gains. This is more or less telling us in a rigid way to remove values from our decisions. Humans are social animals circumscribing our decision within this rule will not help us make the best decision for our children. Non-maleficence, avoiding harm to someone propounds that we cannot be certain about what is the best thing to do for someone but rather employs our common-sense for red-lines. If parents operate within the accepted imaginary line and do not cross it, their request should be accepted and respected.

I have a hunch that one cannot take one as a top value as Campbell attempted to do, but we can reach a better decision during disputes when we relate to the specific clinical experience. The complexity of this case is empirical, valuational and conceptual. It is very vital we look at each case differently, cross-cultural values and the parochial stance of autonomy are factors that need to be considered when making these decisions. The principles of ethics are so intertwined which illustrate their complexity and the ability to balance these tenets in a timely manner is essential when making the decisions, as time could be a significant factor determining life and death. In fact, It would be commonsensical for us to accept a child getting assisted medically if he is suffering, turning to his parents for advice during this time would be irresponsible. Why is Charlie's case so different? 
We have parents requesting an alternative way to keep their child alive even if the chance is theoretical, this should be accommodated. Noticeably, the principles encompassing medical ethics only provide standard guidelines, as we relate the principles to the clinical situation, we find ourselves in the middle of complexities. Most times if applied unbalanced, we arrive at a situation where values and even ingenuities are neglected. Very often, futuristic probable innovation is neglected under the guise of unknown. If explaining a phenomenon is part of scientific endeavour disregarding experimental treatment is antithetical to its course. In Charlie's case, the expert's opinion is paramount, in a way we all explicitly seek objectively verifiable medicine, implicitly accepting its limitation without admitting that we are doing so. If medicine as part of science aspires to seek the unknown, is experimental therapy not a way forward?

At the risk of repeating myself, I do emphasize that the principles and laws are guidelines prescriptively very dominant in resolving differences but we ought to understand that laws and principles are amendments, not commandments subject to change with new information. We all need to ascertain our collective responsibility when making these tough decisions realizing that our interaction with our society constitutes us being human. On that account, our laws and principles should reflect this collective responsibility. If we accept my definition that autonomy of our children is a value that begins in the family, assertion supported by the United Kingdom children act 1989 and United Nations treaty. But in times of conflict belongs to us collectively, we must decide for children that are not biologically ours, as if they were our children.

To unpack the complexities of empirical, valuational and conceptual intertwinement, changing attitudes as an educational objective is a key to our decision making capability. We have observed public outcry about the decision made in London. We all have grappled with the decision. Should Charlie be taken off life support? Should we turn the life-saving tubes off to ease his pain? Are we really sure that Charlie would want his life-saving tube to be turned off? We have had a public discourse whether the decision taken in London is ethical.(Chen, Cai, Zha, \& Shen, 2018) My observation is that during Charlie's dispute, I realize the autonomy of children is a shared duty. It is evident that when doctors and parents disagree, the child suffers. The direction is togetherness and our children deserve more than one principle topping other principles, in short, our children deserve better more than the mere application of non-maleficence or best interest principle. 


\section{Conclusions}

The decision made in London to end Charlie's life is a reminder that ethicists and doctors will continue to make decisions about patient's rights. It is important to consider patient's perspective and this should be beyond the law. Illustrating something legally does not make the law compassionate. History taught us that to be a good member of a society following its rules is necessary but not sufficient. The responsibility of the Other should be something beyond law and the subject ought to be decentered by her responsibility towards the Other. The decision made by the doctors in London is open to different interpretation. Parents' perspective was ditched in the case of Charlie. If they would have permitted Charlie to travel to the US earlier to seek alternative treatment, no law would have been broken, thus making their decision debatable. There is substantial evidence to back the fact that, if the ethical decision was made swiftly Charlie could have been saved due to the brain test performed by the expert. This test shows less severe damage to the brain.

Furthermore, medicine should be a discipline that seeks a balance of objectively verifiable fact and sometimes value-based decisions ought to be taken into account when making decisions about life and death. This case is an example of nothing to lose, the doctors in London should have made a compassionate decision for Charlie to seek alternative treatment in a timely fashion. The denial of his parents' right to autonomy is open to debate considering the children act 1989 and United Nations treaty prioritize the parents as the first line of protection when it comes to their children's livelihood. In a free society, ability to choose our destiny is carved in our law but denied in this case. To die or live, the court should not coerce the people to follow its decision. Charlie's parents were compelled to follow the UK medical opinion, even when a theoretical chance of Hirano's medical opinion was submitted. I cannot argue for the objective nature of the evidence since Hirano and the medical team in London differ in prognosis at the initial stage of the diagnosis. I am not able to see the evidence of certitude that Charlie won't benefit from the experimental therapy. One can infer they have used their fundamental right given to all humans, that is, ability to make a decision, simultaneously denying Charlie's parents exactly the same right for further treatment of their son.

The decision by the doctors to take Charlie off life support is ambiguous. For the doctors involved, they have applied Beneficence(doing good), non-maleficence(avoiding harm) and Justice (fairness in the provision 
of care, upholding EU court judgement) but the autonomy (respecting the patient's wishes was not established). It is my opinion that the doctors and party involved made a fatal error in their judgement when they fail to establish and embed Charlie's autonomy in their decision. There is nonexistence of objectively verifiable evidence to support their claim that their decision to turn off Charlie's life support is with certitude for the benefit of Charlie, they have denied him autonomy and autonomy bestowed on his parents under international treaty ratified by the United Kingdom. The beneficence argument will fail as a result of them ditching Charlie's autonomy because they have failed to balance autonomy and beneficence. In a liberal democracy, people should be able to decide for themselves as long they are not harming anybody and provided the request is not egregious. The non-maleficence (avoiding harm) is also doomed for the same reason. Can the doctors back it up objectively that they have avoided harm to Charlie with certitude? The disregard for alternative treatment earlier in the United States validates my concerns.

Moreover, in the case of the other principle approach, justice in relating to fairness in the provision of care, as I mentioned earlier, the fact that the doctors' opinion is backed by the court does not make the decision humane. The care of the Other ought to be something beyond law and something that is not protected enough by law as Charlie's case illustrated. The perspective of cognitively capable patient's autonomy request within a moral limit cannot be rejected when making a decision about life and death. The doctors in London have adopted a professional-centric approach. Obviously, in this case, when people's values are removed from treatment, it could lead to detrimental effect and irreversible damage. I remain a proponent of an objectively verifiable medicine, it is my opinion that I reserve the right to seek treatment or reject treatment if I am sane to make these decisions. The doctor knows best, so to speak, paternalistic intervention is not the way forward in doctors and patients relationship. The idea of free liberty and the ability to determine man's future are fundamental human right.

In medicine, then, Beneficence,non-maleficence and justice are powerful methods of ethical reasoning, there is a need for these approaches to be used in conjunction with other, more lucid and discursive, approaches. In this Charlie's case, it is recognizable that the doctors in London rely exclusively on beneficence,non-maleficence and justice to make their decisions. The approach that they employ if continues, is likely to endorse as to prevent abusive practices in medicine. The patient's perspectives ought to be established and included. Human values must be considered when 
making ethical decisions. I am sympathetic to the autonomous criteria postulated by another researcher (Beauchamp \& Childress, 2009; "Children Act 1989," 1989), stating for a choice to be autonomous, it must be intentional, made with understanding, cannot be forced, and the subject must be cognitively capable to grasp the process.Charlie's parents fulfil these criteria and the doctors should have put that into consideration when making an ethical decision.

In fine, doctors and ethicists can find themselves in position to make a decision about life and death of their patient. It is suggested that they turn to bioethics for guidance, a confluence of professional centred combined with patient centred approaches ought to be weighed in accordingly when making these tough decisions. Charlie's parents have the right to seek alternative ways to save the life of their child if an opportunity is presented to them, as in this case by US doctors, hence making their request reasonable. Their goal is to exhaust all opportunities to save their child. I think Charlie's denial of potentially life-saving treatment earlier violates one principle of bioethics and one principle of liberal democracy, namely the right of autonomy. Balance, as Aristotle pointed out, it is all about balance. We should not be so sceptical about medical finding that we ignore it simultaneously be ready to spell out its limitation.

Arthur L. Caplan, philosopher and ethicist, has the last word:

People ask, "Is the science going to run ahead of the ethics?" I don't think that's always the problem. I think it's that the science runs ahead of the politics. Bioethics can alert people to something coming down the road, but it doesn't mean policy and politicians are going to pay attention. They tend to respond when there's an immediate crisis. The job of the ethicist, in some ways, is to warn or be prophetic. You can yell loudly, but you can't necessarily get everybody to leave the cinema, so to speak. (Pallarito, 2008).

\section{References}

Ackerman, T. (1982). Why Doctors Should Intervene? The Hastings Center Report, 12(4). doi:http://dx.doi.org/10.2307/3560762

Adu, A. (2017). Charlie Gard's parents donate $£ 1.3$ million fund-raised for treatment to help save other sick children's lives. The Sun.

Beauchamp, T., \& Childress, J. (2009). Principles of biomedical ethics. New York: Oxford University Press.

Chen, H. L., Cai, J. Y., Zha, M. L., \& Shen, W. Q. (2018). Prenatal smoking and postpartum depression: a meta-analysis. J Psychosom Obstet Gynaecol, 1-9. doi:10.1080/0167482X.2017.1415881 
Children Act 1989, https://www.legislation.gov.uk/ukpga/1989/41/introduction (1989).

Fouzder, M. (2017). Baby's parents 'struggling to understand' life support ruling. Law Society Gazette. Retrieved from https://www.lawgazette.co.uk/law/babys-parents-struggling-tounderstand-life-support-ruling/5060646.article

Fulford, K., Gillett, G., \& Soskice, J. (1994). Medicine and moral reasoning. England: Cambridge University Press.

HUDOC - European Court of Human Rights. (2017). Retrieved from https://hudoc.echr.coe.int/eng\# \{"itemid":"001-175359"

Pallarito, K. (2008). Supplement: Art Caplan. The Scientist. Retrieved from https://www.the-

scientist.com/?articles.view/articleNo/25955/title/Supplement-Art-Caplan/

Rabin, R. (2017). New York Hospital Offers to Treat British Baby With Rare Disease. Nytimes.com. Retrieved from https://www.nytimes.com/2017/07/06/health/uk-infant-charliegard-ny-hospital.html

Walker, P. (2017). Charlie Gard case: May says hospital will consider any offers. The Guardian.

Yates, \& Anor. (2017). Great Ormond Street Hospital For Children NHS

Foundation Trust \& Anor. Retrieved from

http://www.bailii.org/ew/cases/EWCA/Civ/2017/410.html 